Special issue of the International Conference on Computational and Experimental Science and Engineering (ICCESEN 2014)

\title{
Predicting the Poisson Ratio of Lightweight Concretes using Artificial Neural Network
}

\author{
M. Davraz ${ }^{a}$, Ş. KilinçARslan ${ }^{a, *}$ And H. CEYlan ${ }^{b}$ \\ ${ }^{a}$ Suleyman Demirel University, Natural and Industrial Building Material Application and Research Center, \\ Isparta, Turkey \\ ${ }^{b}$ Suleyman Demirel University, Department of Construction, Technical Sciences Vocation School, Isparta, Turkey
}

\begin{abstract}
Artificial neural network is generally information processing system and a computer program that imitates human brain neural network system. By entering the information from outside, artificial neural network can be trained on examples related to a problem, so that modeling of the problem is provided. In this study, compressive strength, Poisson ratio of the lightweight concrete specimens, which have different natural lightweight aggregates, were modeled with artificial neural network. The data which were provided by artificial neural network model were compared with the data obtained from experimental study and a good agreement was determined between the results.
\end{abstract}

DOI: 10.12693/APhysPolA.128.B-184

PACS: 62.20.dj

\section{Introduction}

Lightweight aggregate concretes (LWAC) are known as very attracting concretes because of their good sound and heat insulation properties, reducing the dead load of a structure, well fire resistance and having high freezethawing resistance [1]. The use of LWAC due to superior insulation properties are becoming widespread day by day to produce walls, flooring and roofing constructions, panel and pre-cast units. Elasticity modulus of LWAC is lower than the conventional concretes and the Poisson ratio is relatively higher. The aggregate properties are very important fact on elasticity modulus of even normal weight concrete.

The recent developments in the field of artificial neural network (ANN) technology, a sub-field of artificial intelligence, have been serving to solve various problems encountered in civil engineering processes. What makes this possible in dealing with civil engineering problems is ANN capability of drawing directly from examples. To use ANNs to their fullest potential in the field of engineering, it needs to shorten the adaptation time without losing from the stability of the network optimal state [2]. The basic rationale behind designing a neural networkbased model to predict certain material behavior is training a neural network based on the results of prior experiments with that material. The performance of the trained neural network depends on the extent to which the experimental results contain the required information on the material behavior [3]. In this paper, ANN models have been developed to predict the Poisson ratio of LWAC.

* corresponding author; e-mail: semsettinkilincarslan@sdu.edu.tr

\section{Experimental \\ 2.1. Properties of materials}

Ordinary Portland cement CEM I 42.5R was used throughout the research in concrete mixtures as a binding material. Basically six different aggregate types were used in this study to make the LWAC mixtures with cement. Two different granulometric designs for aggregates were used in this study. In the first group of granulometric design, $60 \%$ aggregate amount at $4 / 8 \mathrm{~mm}$ size and $40 \%$ aggregate amount at $0 / 4 \mathrm{~mm}$ size were used throughout the research. In the second group of granulometric design, $60 \%$ aggregate amount at $0 / 4 \mathrm{~mm}$ size and $40 \%$ aggregate amount at $4 / 8 \mathrm{~mm}$ size were used in the mixtures, too.

TABLE I

Concrete mixture designs for the normal and LWA. Cement $400 \mathrm{~kg}$, water $100 \mathrm{~kg}$, plasticizer $8 \mathrm{~kg}$.

\begin{tabular}{c|c|c|c}
\hline \hline \multirow{2}{*}{ Code } & \multicolumn{2}{|c|}{ Aggregate $[\mathrm{kg}]$} & $\begin{array}{c}\text { Density of fresh } \\
\text { concrete }\left[\mathrm{kg} / \mathrm{m}^{3}\right]\end{array}$ \\
\cline { 2 - 3 } & coarse $(4 / 8 \mathrm{~mm})$ & fine $(0 / 4 \mathrm{~mm})$ & 1.416 \\
LC I & 440 & 408 & 1.194 \\
IGP I & 273 & 352 & 1.093 \\
NP I & 291 & 234 & 1.263 \\
KVS I & 352 & 343 & 1.852 \\
ECA I & 730 & 553 & 1.393 \\
LC II & 293 & 340 & 1.473 \\
IGP II & 182 & 612 & 1.279 \\
KP II & 194 & 529 & 1.113 \\
NP II & 234 & 514 & 1.317 \\
KVS II & 487 & 830 & 1.885 \\
ECA II & 323 & 511 & 1.402 \\
\hline IKP - Isparta Karakaya pumice, IGP — Isparta Gelincik \\
pumice, KP - Kayseri pumice, NP - Nevsehir pumice, \\
KVS - Kula Volcanic slag, ECA - expanded clay aggregate
\end{tabular}


Totally fourteen different concrete mixtures were prepared to compare the mechanical properties of concrete samples made by LWA having two different granulometric designs. The mixture proportions were given in Table I.

Twelve cube samples in $150 \mathrm{~mm}$ size were cast for each mixture to analyze the uniaxial compressive strength and three prismatic concrete samples in $100 \times 100 \times 350 \mathrm{~mm}^{3}$ size were also cast for determining the flexural strength of concrete. Concrete samples were extracted after $24 \mathrm{~h}$ from the moulds and they were kept in thermostatic curing water tanks until the testing time.

\subsection{Mechanical testing applied}

Oven dry bulk density of concrete samples with normal and LWA was determined according to the principles of
TS EN 12390-7 standard [4]. The uniaxial compressive strength tests were carried out at 3, 7 and 28 days curing time on $150 \mathrm{~mm}$ cube samples in accordance with TS EN 12390-3 standard [5]. The flexural strength tests were also carried out only at 28 days curing time on $100 \times$ $100 \times 350 \mathrm{~mm}^{3}$ prismatic samples in accordance with TS EN 12390-5 standard [6]. Static elasticity modulus and the Poisson ratio of $150 \times 300 \mathrm{~mm}^{3}$ in size of concrete samples cured at 28 days were determined according to the principles of TS 3502 standard [7].

\section{Results and discussion}

\subsection{Experimental results for $L W A C$}

Determined Poisson rates of LWAC experiment - results are given in Table II.

Experimental results of LWAC samples [8].

TABLE II

\begin{tabular}{c|c|c|c|c|c|c|c|c|c|c|c|c}
\hline \hline Specimen & IKP & IGP & KP & NP & KVS & ECA & IKP & IGP & KP & NP & KVS & ECA \\
\cline { 2 - 15 } & \multicolumn{9}{|c|}{ I } \\
\hline$\rho\left[\mathrm{kg} / \mathrm{m}^{3}\right]$ & 1380 & 1220 & 1050 & 1100 & 1450 & 1220 & 1420 & 1310 & 1140 & 1190 & 1790 & 1340 \\
$f_{c k}[\mathrm{MPa}]$ & 10.9 & 11.0 & 8.6 & 6.5 & 7.3 & 9.4 & 16.9 & 16.5 & 13.0 & 15.3 & 14.3 & 20.0 \\
$f_{c f}[\mathrm{MPa}]$ & 2.38 & 2.82 & 2.73 & 1.92 & 2.01 & 2.89 & 4.23 & 4.81 & 4.78 & 5.13 & 5.01 & 6.15 \\
$E_{s}[\mathrm{GPa}]$ & 4.01 & 4.45 & 4.14 & 2.29 & 2.34 & 3.82 & 8.31 & 7.87 & 5.01 & 7.03 & 6.36 & 10.13 \\
$\nu_{s}$ & 0.27 & 0.23 & 0.24 & 0.21 & 0.27 & 0.21 & 0.23 & 0.22 & 0.23 & 0.20 & 0.23 & 0.21 \\
\hline
\end{tabular}

$\rho$ - density, $f_{c k}$ - compressive strength, $f_{c f}$ - flexural strength, $E_{s}$ - static elasticity

modulus, $\nu_{s}$ - static Poisson rate

\subsection{Artificial neural networks}

The ANN modeling consists of two steps: the first step is to train the network; the second step is to test the network with data, which were not used in training step [9]. Neural networks have been trained to perform complex functions in various fields of application including pattern recognition, identification, classification, speech, vision, and control systems [10]. Artificial neural networks model developed in this research has four neurons (variables) in the input layer and one neuron in the output layer as illustrated in Fig. 1. One hidden layer with eight neurons was used in the architecture because of its minimum percentage error values for training and testing sets. While modeling networks, density, compressive strength, flexural strength and elasticity modulus were used as inputs and the Poisson rate was used as output. For training set, 24 samples ( $69 \%$ of all samples) were selected and the residual data (11-31\% of all samples) were selected as test set. The values of the training and test data were normalized between 0 and 1 using Eq. (1):

$$
F=\left(F_{i}-F_{\max }\right) /\left(F_{\max }-F_{\min }\right) .
$$

In this equation $F$ represents normalized value, $F_{i}$ represents $i$. Value of measured values and $F_{\max }$ and $F_{\min }$ represent maximum and minimum values of measured values. The back-propagation learning algorithm was

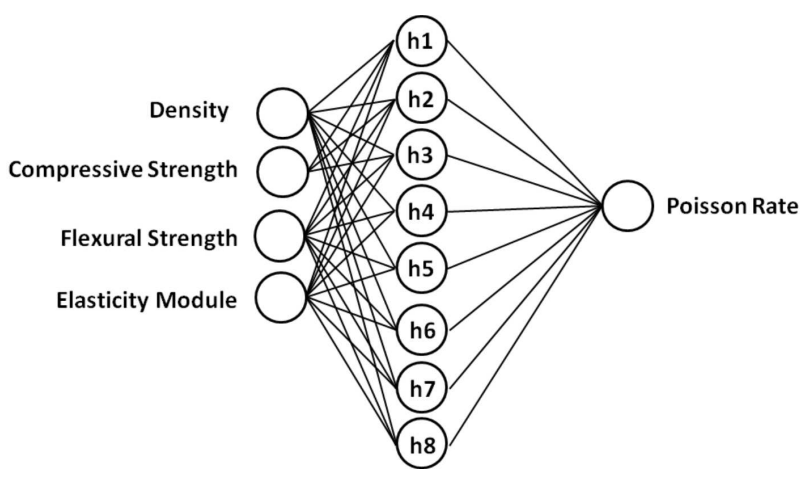

Fig. 1. The structure of 481 model (4 input, 8 hidden and 1 output).

used in feed-forward with one hidden layer. Logarithmic sigmoid transfer function was used as the activation function for hidden layers and output layers. The learning rate and momentum are the parameters that affect the speed of convergence of the back-propagation algorithm. 1000 learning cycles were used while training all networks. A learning rate of 0.001 and momentum 0.1 , were fixed for selected network after training and model selection was completed for training set. The trained 
networks were used to run a set of test data. All of the developed networks (341-361-381-3101) were compared with experimental results and $R^{2}$ values of testing results are shown in Table III. The selected network after training and model selection was completed for training set. The ANN (3101) has the best correlation with experimental results for both training and testing sets that are displayed in Fig. 2a, b.

\section{TABLE III}

Results obtained from training and testing the ANN and correlations with the experimental results.

\begin{tabular}{c|c|c|c|c}
\hline \hline Model & 341 & 361 & 381 & 3101 \\
\hline training $\left(R^{2}\right)$ & 0.727 & 0.891 & 0.916 & 0.932 \\
testing $\left(R^{2}\right)$ & 0.970 & 0.942 & 0.963 & 0.975
\end{tabular}

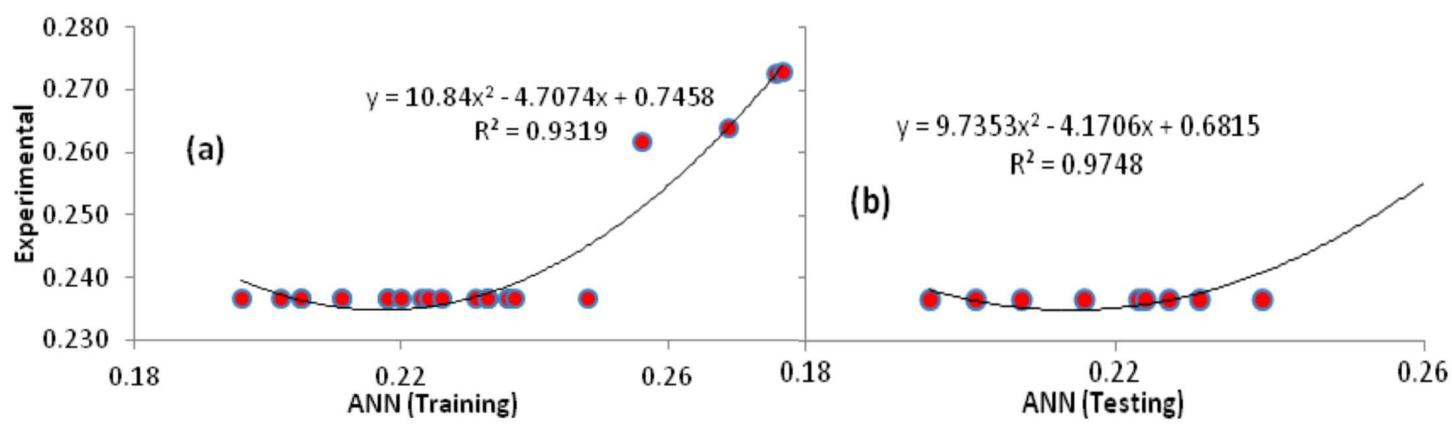

Fig. 2. Correlation between experimental and ANN 3101 model training (a) and testing (b).

\section{Conclusions}

ANN models were developed to predict the Poisson rate for various density, compressive strength, flexural strength and elasticity modules without experimenting. Model developed in the study were trained by input and output data. Randomly selected 14 experimental data sets were used as test data to test the trained ANN. It was found that, when these testing data sets were applied to both trained ANNs, the Poisson rates were very close to the actual experimental data. Prediction of the Poisson rate of LWAC by using artificial neural network has proved to be a practical and effective method.

\section{References}

[1] S.C. Kok, Z. Min-Hong, Cement Concrete Res. 25, 276 (2002).

[2] J. Hertz, A. Krogh, R. Palmer, Introduction to the Theory of Neural Networks, Addison-Wesley, Redwood City 1991.
[3] A. Oztaş, Constr. Build Mater. 20, 769 (2006).

[4] TS EN 12390-7, Testing hardened concrete-Part \%: Density of hardened concrete, TSE, Ankara 2002.

[5] TS EN 12390-3, Testing hardened concrete-Part 3: Compressive strength of test specimens, TSE, Ankara 2003.

[6] TS EN 12390-5, Testing hardened concrete-Part 5: Flexural strength of test specimens, TSE, Ankara 2002.

[7] TS 3502, Test method for static modulus of elasticity and Poisson ratio of concrete in compression, TSE, Ankara 1981.

[8] M. Davraz, H. Ceylan, S. Kilıncarslan, Acta Phys. Pol. A 127, 1246 (2015).

[9] C. Basyigit, I. Akkurt, S. Kılıncarslan, A. Beycioglu, Neural Comput. Appl. 19, 507 (2010).

[10] S. Terzi, Construct. Build Mater. 21, 590 (2007). 